\title{
Theorems and rules connecting bond energy and bond order with electronegativity equalization and hardness maximization
}

\author{
László von Szentpály ${ }^{1}$ (D)
}

Received: 8 November 2019 / Accepted: 13 February 2020 / Published online: 24 February 2020

(c) The Author(s) 2020

\begin{abstract}
Bond orders are attributed a new role in rationalizing the electronegativity equalization (ENE) and maximum hardness $(\mathrm{MH})$ rules. The following rules and theorems are formulated for chemical species (atoms, groups, molecules), X, Y, XY, their ionization energies, $I$, electron affinities, $A$, electronegativity, $\chi=1 / 2(I+A)$, and chemical hardness, $\eta=1 / 2(I-A)$. Rule 1 Sanderson's principle of electronegativity equalization is supported (individual deviations $<10 \%$ ) by association reactions, $\mathrm{X}+\mathrm{Y} \rightarrow \mathrm{XY}$, if the ionic bond dissociation energies are equal, $D\left(\mathrm{XY}^{+}\right)=D\left(\mathrm{XY}^{-}\right)$, or, equivalently, if the relative bond orders are equal, $\mathrm{BO}_{\text {rel }}\left(\mathrm{XY}^{+}\right)=\mathrm{BO}_{\text {rel }}\left(\mathrm{XY}^{-}\right)$. Rule 2 Sanderson's principle of electronegativity equalization is supported (individual deviations $<10 \%$ ) by association reactions, $\mathrm{X}+\mathrm{Y} \rightarrow \mathrm{XY}$, if the formal bond orders, FBO, of the ions are equal, FBO $\left(\mathrm{XY}^{+}\right)=\mathrm{FBO}\left(\mathrm{XY}^{-}\right)$. Theorem 1 The electronegativity is not equalized by association reactions, $\mathrm{X}+\mathrm{Y} \rightarrow \mathrm{XY}$, if the formal bond orders of the ions differ, $\mathrm{FBO}\left(\mathrm{XY}^{+}\right)-\mathrm{FBO}\left(\mathrm{XY}^{-}\right) \neq 0$. Theorem 2 The chemical hardness is increased by nonpolar bond formation, $2 \mathrm{X} \rightarrow \mathrm{X}_{2}$, if (and for atomic $\mathrm{X}$ : if and only if) the sum $\mathrm{BO}_{\text {rel }}\left(\mathrm{X}_{2}^{+}\right)+\mathrm{BO}_{\text {rel }}\left(\mathrm{X}_{2}^{-}\right)<2$. Rule 3 The chemical hardness is decreased, thus the "maximum hardness principle" violated by association reactions, $\mathrm{X}+\mathrm{Y} \rightarrow \mathrm{XY}$, if (but not only if) $\mathrm{BO}_{\text {rel }}\left(\mathrm{XY}^{+}\right)+\mathrm{BO}_{\text {rel }}\left(\mathrm{XY}^{-}\right)>2$. The theorems are proved, and the rules corroborated with the help of elementary thermochemical cycles according to the first law of thermodynamics. They place new conditions on the "structural principles" ENE and MH. The performances of different electronegativities and hardness scales are compared with respect to ENE and $\mathrm{MH}$. The scales based on valence-state energies perform consistently better than scales based on ground-state energies. The present work provides the explanation for the order of magnitude better performance of valence-state ENE compared to that of the ground-state ENE. We here show by a new approach that the combination of several fuzzy concepts clarifies the situation and helps in defining the range of validity of rules and principles derived from such concepts.
\end{abstract}

Keywords Electronegativity $\cdot$ Electronegativity equalization $\cdot$ Chemical hardness $\cdot$ Valence state $\cdot$ Valency $\cdot$ Bond dissociation energy $\cdot$ Formal bond order $\cdot$ Relative bond order $\cdot$ Thermochemical cycles $\cdot$ Hardness maximization . Structural principle $\cdot$ Conceptual DFT

\section{Introduction}

Bond orders (BOs) are normally not mentioned in connection with "structural principles," such as electronegativity equalization (ENE) and maximum hardness (MH). An important role is here attributed to bond orders in

Published as part of the special collection of articles derived from the Chemical Concepts from Theory and Computation.

László von Szentpály

1szentpaly@yahoo.com

1 Institut für Theoretische Chemie, Universität Stuttgart, Pfaffenwaldring 55, 70569 Stuttgart, Germany formulating some of the most relevant concepts, rules and principles, which describe and predict chemical behavior. The aim is a much improved understanding of the ENE and MH rules or principles, which are particularly connected to density functional theory (DFT) [1-3]. Electronegativity, chemical hardness, bond order, valency and valence-state energy are not directly measurable properties. Interpretations are needed to characterize them and attribute quantitative scales and values to them. Hence, they are derived theoretically from results of measurements.

The formal bond order (FBO) is defined by half the difference between the number of bonding electrons and that of antibonding electrons 
FBO $=1 / 2\left(N_{\text {bonding }}-N_{\text {antibonding }}\right)$

The FBO, also called "chemical bond order" [4], offers a quick estimate for the bond strength from valence bond structures [5]. It takes on positive integral values for an integral number of shared electron pairs between the two atoms (groups). Half-integral FBOs arise if an unpaired electron is involved in the bond, e.g., in $\mathrm{H}_{2}^{+}$. The FBO is strongly linked to the valencies of the atoms (groups) forming the bond. The valency $(V)$ is defined as the number of half-filled (singly occupied) orbitals of the species [6-13]. Some atoms in the periodic system of elements are attributed several valencies, which depend on the molecular environment. Thus, a carbon atom in its ground state (GS) is divalent, $V(C)=2$, whereas tetravalent carbon is promoted into a valence state (VS) with $V\left(C_{\mathrm{VS}}\right)=4$. The electron configuration of the atom in the molecule (AiM) is not that of the free atom in its ground state, as already a diatomic molecule contains various neutral and/or ionic valence structures. The energy of an atom or ion in its Mulliken type VS [6-13] is the averaged energy of all spectroscopic states belonging to a valence configuration, e.g., the divalent $\mathrm{O}_{\mathrm{vs}}$ atom in states ${ }^{3} \mathrm{P}$ and ${ }^{1} \mathrm{D}$ of configuration $s^{2} p^{2} p^{1} p^{1}$ and the monovalent $\mathrm{O}_{\mathrm{VS}}^{+}$ in the states ${ }^{2} \mathrm{D}$ and ${ }^{2} \mathrm{P}$ of configuration $s^{2} p^{2} p^{1}[7,8]$. The ground state ${ }^{4} \mathrm{~S}$ of trivalent $\mathrm{O}_{\mathrm{GS}}^{+}$belongs to the configuration $s^{2} p^{1} p^{1} p^{1}$. The valency is important for Mulliken's atomic electronegativity [6-10] and its molecular generalization, the valence-pair-affinity, $\alpha_{\mathrm{VP}}$ [11-13]; see "Appendix." In valence states, the valency of $\mathrm{X}_{\mathrm{VS}}^{+}$and $\mathrm{X}_{\mathrm{VS}}^{-}$is always

$V\left(\mathrm{X}_{\mathrm{VS}}^{+}\right)=V\left(\mathrm{X}_{\mathrm{VS}}^{-}\right)=V\left(\mathrm{X}_{\mathrm{VS}}\right)-1$

This necessary condition is independent of particular definitions of the VS energy [6-14]. The VS and GS valencies may be identical, e.g., for $V(\mathrm{H})=1, V\left(\mathrm{H}^{+}\right)=V\left(\mathrm{H}^{-}\right)=0$. However, they differ for ions, if the neutral atom (group, or fragment) contains doubly occupied ("lone pair") orbitals in its highest subshell, e.g., $\mathrm{Be}, \mathrm{Mg}, \mathrm{O}, \mathrm{S}, \mathrm{F}, \mathrm{Cl}$, etc. In such cases, the ionization requiring the lowest energy, $I_{0, v}$, increases the valency by 1 , as the electron is removed from the doubly occupied orbital. The valency of ground state $\mathrm{O}_{\mathrm{GS}}^{+}$ is 3; that of $\mathrm{Cl}_{\mathrm{GS}}^{+}$is 2 . The VS valencies are $V\left(\mathrm{O}_{\mathrm{VS}}^{+}\right)=1$ and $V\left(\mathrm{Cl}_{\mathrm{VS}}^{+}\right)=0$. The formal bond order of the molecule, $\mathrm{XY}$, formed by atoms $\mathrm{X}$ and $\mathrm{Y}$ is

$\mathrm{FBO}(\mathrm{XY})=1 / 2[V(\mathrm{X})+V(\mathrm{Y})]$

For molecules and their ions, the strict Wigner-Witmer symmetry correlation rules $[15,16]$ assign the molecular state(s) appropriate for the constituent VS atoms and/or ions [6-14]. Combined with Eq. (2), the VS formal bond orders are reduced by $1 / 2$
$\mathrm{FBO}\left(\mathrm{XY}_{\mathrm{VS}}^{+}\right)=\mathrm{FBO}\left(\mathrm{XY}_{\mathrm{VS}}^{-}\right)=\mathrm{FBO}\left(\mathrm{XY}_{\mathrm{VS}}\right)-1 / 2$

Again, this is independent of particular definitions of the VS energy [6-14]. The difference in the VS and GS bond orders is exemplified on $\mathrm{Cl}_{2}$. For the GS, the FBO increases by ionization to $\mathrm{FBO}\left(\mathrm{Cl}_{2}{ }_{\mathrm{GS}}\right)=3 / 2$, as an electron is removed from an antibonding molecular orbital (MO). The bond dissociation energy, $D_{0}\left(\mathrm{Cl}_{2}{ }^{+}\right)=3.95 \mathrm{eV}>D_{0}$ $\left(\mathrm{Cl}_{2}\right)=2.48 \mathrm{eV}$, is increased by about $50 \%$ [17]. In contrast, the VS ionization energy $I_{\mathrm{VS}, v}\left(\mathrm{Cl}_{2}\right)=16.08 \mathrm{eV}$ [11-13] removes an electron from the bonding $\sigma_{\mathrm{g}} \mathrm{MO}$, reduces the formal BO by $1 / 2$ and weakens the bond to $D_{\mathrm{Vs}}$ $\left(\mathrm{Cl}_{2}{ }^{+}\right) \approx 1.50 \mathrm{eV}$.

The relative bond order, $\mathrm{BO}_{\text {rel }}$, of a molecular ion, $\mathrm{XY}^{+}$or $\mathrm{XY}^{-}$, is the bond dissociation energy, $D$, of the ion divided by that of the neutral molecule [18-20]

$\mathrm{BO}_{\text {rel }}\left(\mathrm{XY}^{+}\right)=D\left(\mathrm{XY}^{+}\right) / D(\mathrm{XY})$

$\mathrm{BO}_{\text {rel }}\left(\mathrm{XY}^{-}\right)=D\left(\mathrm{XY}^{-}\right) / D(\mathrm{XY})$

It will be important to discuss the varieties of $\mathrm{BO}_{\text {rel }}$ values for different states, namely ground states and valence states.

Sanderson's electronegativity equalization principle [21, 22] postulates, when atoms combine to a molecule, the atomic electronegativities, $\chi$ (at), will be equalized to their geometric average, $\langle\chi(\mathrm{at})\rangle_{\mathrm{GM}}$,

$\chi(\mathrm{mol})=\langle\chi(\mathrm{at})\rangle_{\mathrm{GM}}$

However, recent large-scale examinations unveiled alarmingly large deviations from Eq. (7), if ground-state electronegativities are used [11, 12, 23]. The present article systematically sheds new light on the reasons for large deviations. Electronegativity is here considered according to: (1) Mulliken's atomic scale, $\chi_{\mathrm{M}}=1 / 2\left(I_{\mathrm{VS}, \text { at }}+A_{\mathrm{VS}, \text { at }}\right)$ [6-10], and its generalization to molecules $\alpha_{\mathrm{VP}}=1 / 2\left(I_{\mathrm{VS}, \mathrm{mol}}+A_{\mathrm{VS}, \mathrm{mol}}\right)$ [11-13] (here both symbolized by $\chi_{\mathrm{VS}}$ ), where $I_{\mathrm{VS}}$ and $A_{\mathrm{VS}}$ are valence-state ionization energies and electron affinities; (2) Parr and coworkers' $[1,2,24,25]$ scale, $\chi_{0}=1 / 2\left(I_{0}+A_{0}\right)$, taking ground-state values, $I_{0}$ and $A_{0}$, which frequently differ significantly from Mulliken's VS data.

Parr and Pearson originally introduced the chemical hardness $[3,26-28]$ as

$\eta=1 / 2\left(I_{0, v}-A_{0, v}\right)$

It quantifies the resistance to charge flow and provides information on the reactivity of atoms and molecules [1, $3,12,26-28]$. Pearson found an empirical rule drawn from comparisons between different compounds [3, 27, 28]: "There seems to be a rule of nature that molecules arrange themselves so as to be as hard as possible," dubbed the maximum hardness $(\mathrm{MH})$ principle or rule. In chemical reactions, 
atoms and molecules should produce the hardest possible species [29]. A formal proof has been obtained only under the unrealistic conditions that the electronegativity and the external potential, $v(\mathbf{r})$, do not change during the reactions [30]. The validity of a "relaxed" version of MH for chemical reactions has been checked numerically at various DF approximation (DFA) levels by comparing the average hardness values of the reactants to those of the products [31, 32]. However, the computed hardness changes drastically, as one changes the DFA level $[31,32]$. Therefore, the pros and cons could not be rationalized as yet. The difference between the molecular hardness $\eta$ (mol) and the arithmetic mean of atomic hardness, $\langle\eta(\mathrm{at})\rangle_{\mathrm{AM}}$, values is denoted as hardness increase

$\Delta \eta=\eta(\mathrm{mol})-\langle\eta(\mathrm{at})\rangle_{\mathrm{AM}}=\eta(\mathrm{mol})-n^{-1} \sum \eta(\mathrm{at})$

The chemical hardness is here considered both in Pearson's and Parr's original ground-state scale [1, 3, 26, 27], $\eta_{0}=1 / 2\left(I_{0, v}-A_{0, v}\right)$, and its equivalent, the valence-state hardness, $\eta_{\mathrm{VS}}=1 / 2\left(I_{\mathrm{VS}, v}-A_{\mathrm{VS}, v}\right)[9,11-13]$. For details of the derivations, see "Appendix." For the formulation of general rules and theorems, the subscripts VS and 0 are omitted, unless they are needed. Thus, $\chi$ stands for $\chi_{0}, \chi_{\mathrm{M}}$ and $\alpha_{\mathrm{VP}}$, as discussed in "Appendix."

\section{Theorems and rules based on thermodynamic cycles}

We specify the conditions for (1) electronegativity equalization and (2) hardness increase in exothermic association reactions, $\mathrm{X}+\mathrm{Y} \rightarrow \mathrm{XY}$, using thermochemical cycles based on the first law of thermodynamics. Consider atoms or groups as reactants, $R=\{\mathrm{X}, \mathrm{Y}\}$, and their products, $P=\left\{\mathrm{X}_{2}\right.$, $\mathrm{XY}$, with corresponding cations, $\mathrm{P}^{+}$, and anions, $\mathrm{P}^{-}$. Figure 1 illustrates the bond formation between $\mathrm{X}$ and $\mathrm{Y}$ and displays the "ingredients" needed to discuss the ENE and $\mathrm{MH}$ rules. Thermochemical cycles connect the bond dissociation energies, $D(\mathrm{P}), D\left(\mathrm{P}^{+}\right)$and $D\left(\mathrm{P}^{-}\right)$to the ionization energies, $I$, and electron affinities, $A$, of the reactants and their product. We use $I(\mathrm{X}) \leq I(\mathrm{Y})$ and $A(\mathrm{X}) \leq A(\mathrm{Y})$ and thus $\Delta \chi(\mathrm{R})=\chi(\mathrm{Y})-\chi(\mathrm{X}) \geq 0$ and focus on two cycles

$$
\begin{aligned}
& I_{a}(\mathrm{P})+D\left(\mathrm{P}^{+}\right)-I(\mathrm{X})-D(\mathrm{P})=0 \\
& A_{a}(\mathrm{P})+D(\mathrm{P})-A(\mathrm{Y})-D\left(\mathrm{P}^{-}\right)=0
\end{aligned}
$$

The sum of Eqs. (10) and (11)

$$
2 \chi_{a}(\mathrm{P})+D\left(\mathrm{P}^{+}\right)-I(\mathrm{X})-A(\mathrm{Y})-D\left(\mathrm{P}^{-}\right)=0
$$

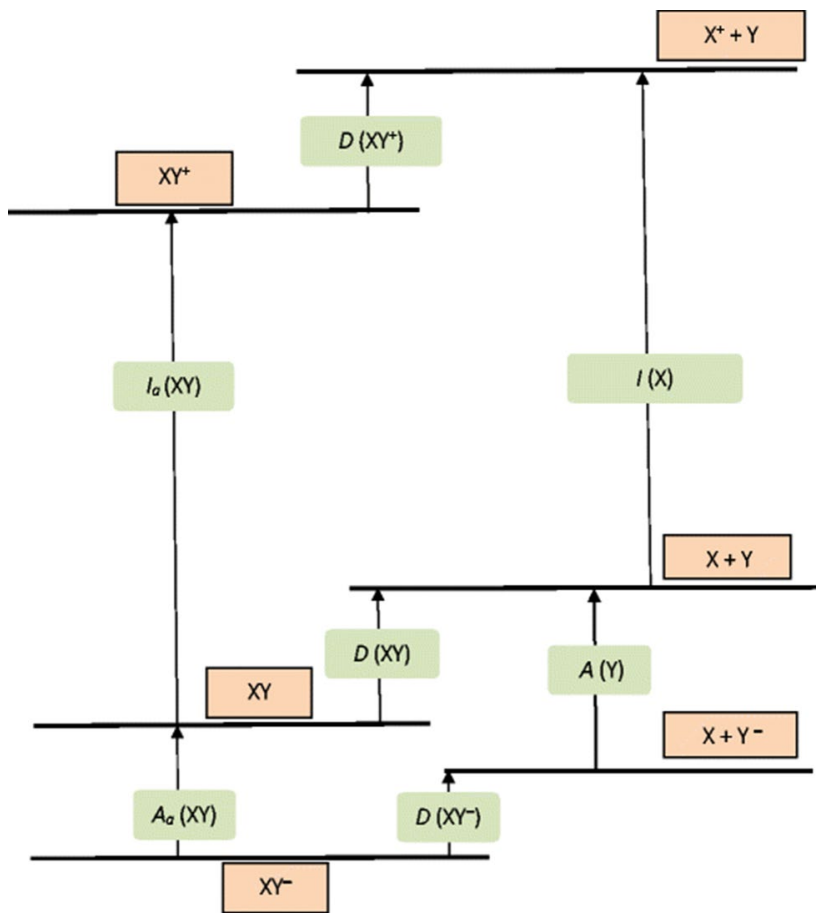

Fig. 1 Thermochemical cycles illustrating the bond formation between the chemical species, $X$ and $Y$, see Eqs. (10)-(12) and (23). Adiabatic $I_{a}(\mathrm{XY})$ and $A_{a}(\mathrm{XY}), I(\mathrm{X})$ and $A(\mathrm{Y})$ values of reactants, and bond dissociation energies, $D(\mathrm{XY}), D\left(\mathrm{XY}^{+}\right)$, and $D\left(\mathrm{XY}^{-}\right)$

determines the product's adiabatic electronegativity, $\chi_{a}$ $(\mathrm{P})=1 / 2\left[I_{a}(\mathrm{P})+A_{a}(\mathrm{P})\right]$, which normally is close to the vertical electronegativity, $\chi_{v}(\mathrm{P}) \approx \chi_{a}(\mathrm{P})$, since $I_{a}(\mathrm{P}) \leq I_{v}(\mathrm{P})$, but $A_{a}(\mathrm{P}) \geq A_{v}(\mathrm{P})$

$$
\begin{aligned}
\chi_{\mathrm{a}}(\mathrm{P}) & =1 / 2\left[D\left(\mathrm{P}^{-}\right)-D\left(\mathrm{P}^{+}\right)+\chi(\mathrm{X})+\eta(\mathrm{X})+\chi(\mathrm{Y})-\eta(\mathrm{Y})\right] \\
& =1 / 2\left[D\left(\mathrm{P}^{-}\right)-D\left(\mathrm{P}^{+}\right)\right]+\langle\chi(\mathrm{R})\rangle_{\mathrm{AM}}-1 / 2 \Delta \eta(\mathrm{R})
\end{aligned}
$$

We have a positive $\Delta \eta(\mathrm{R})=\eta(\mathrm{Y})-\eta(\mathrm{X}) \geq 0$, due to $\Delta \chi$ (R) $\geq 0$, and the high-quality linear relationship between $\chi$ (at) and $\eta$ (at), found by Bratsch for the main group elements [33], is

$\eta(\mathrm{at})=(0.60 \pm 0.11) \chi(\mathrm{at})$

It is important that the bond dissociation energy $D(\mathrm{P})$ of the neutral product cancels out by adding Eqs. (10) and (11). The thermochemical cycles provide essential support for the new rules.

Rule 1 reads: Sanderson's principle is supported (individual deviations: $<10 \%$ ) by association reactions, $X+Y \rightarrow X Y$, if the ionic dissociation energies are equal, $D\left(\mathrm{XY}^{+}\right)=D$ $\left(\mathrm{XY}^{-}\right)$, or, equivalently, if the relative bond orders are equal, $\mathrm{BO}_{\text {rel }}\left(\mathrm{XY}^{+}\right)=\mathrm{BO}_{\text {rel }}\left(\mathrm{XY}^{-}\right)$.

The arithmetic mean $\langle\chi(\mathrm{R})\rangle_{\mathrm{AM}}$ differs from the product's adiabatic electronegativity by 


$$
\begin{gathered}
\langle\chi(\mathrm{R})\rangle_{\mathrm{AM}}-\chi_{a}(\mathrm{P})=1 / 2\left[D\left(\mathrm{P}^{+}\right)-D\left(\mathrm{P}^{-}\right)\right] \\
+1 / 2 \Delta \eta(\mathrm{R}) \geq 1 / 2\left[D\left(\mathrm{P}^{+}\right)-D\left(\mathrm{P}^{-}\right)\right]
\end{gathered}
$$

As Sanderson's principle emphasizes the geometric average, $\langle\chi(\mathrm{R})\rangle_{\mathrm{GM}}$, we consider approximations to the classical AM-GM inequality [34, 35], which are most frequently used in applications of economics and finance. Most of them involve the variance, $\sigma^{2}$, and/or the standard deviation, $\sigma[34$, 35]. Accordingly, for the sample size, $n \geq 2$, we have

$\langle\chi\rangle_{\mathrm{GM}} \geq\langle\chi\rangle_{\mathrm{AM}}-(n-1)^{1 / 2} \sigma$

Some applications in economics and finance even replace $\geq$ by "approximately equal" $(\approx)[34,35]$. For two reagents $\mathrm{R}, n=2$, the result is

$\langle\chi(\mathrm{R})\rangle_{\mathrm{GM}} \geq\langle\chi(\mathrm{R})\rangle_{\mathrm{AM}}-1 / 2 \Delta \chi(\mathrm{R})$

In support, consider the relation

$$
\begin{aligned}
& {\left[\langle\chi(\mathrm{R})\rangle_{\mathrm{AM}}\right]^{2}-\left[\langle\chi(\mathrm{R})\rangle_{G M}\right]^{2}} \\
& \quad=1 / 4[\chi(\mathrm{Y})+\chi(\mathrm{X})]^{2}-\chi(\mathrm{Y}) \chi(\mathrm{X}) \\
& \quad=1 / 4[\chi(\mathrm{Y})-\chi(\mathrm{X})]^{2}=[1 / 2 \Delta \chi(\mathrm{R})]^{2} \\
& \langle\chi(\mathrm{R})\rangle_{\mathrm{AM}}-\langle\chi(\mathrm{R})\rangle_{\mathrm{GM}} \\
& \quad \leq\left\{\left[\langle\chi(\mathrm{R})\rangle_{\mathrm{AM}}\right]^{2}-\left[\langle\chi(\mathrm{R})\rangle_{\mathrm{GM}}\right]^{2}\right\}^{1 / 2}=1 / 2 \Delta \chi(\mathrm{R})
\end{aligned}
$$

which rearranges to Eq. (17).

Based on Eq. (14), we consider $\Delta \eta(\mathrm{R}) \approx 0.60 \Delta \chi(\mathrm{R})$, replace $\Delta \chi(\mathrm{R})>0$ by the smaller $\Delta \eta(\mathrm{R})>0$ and reduce the amount of inequality to ca. $60 \%$. Then, Eqs. (14) and (19) combine to

$$
\begin{aligned}
& \langle\chi(\mathrm{R})\rangle_{\mathrm{GM}}-\chi_{a}(\mathrm{P}) \approx\langle\chi(\mathrm{R})\rangle_{\mathrm{AM}}-1 / 2 \Delta \eta(\mathrm{R}) \\
& -\chi_{a}(\mathrm{P}) \approx 1 / 2\left[D\left(\mathrm{P}^{+}\right)-D\left(\mathrm{P}^{-}\right)\right]
\end{aligned}
$$

Assuming $\chi_{v}(\mathrm{P}) \approx \chi_{a}(\mathrm{P})$, we present a new criterion for testing Sanderson's postulate of geometric electronegativity equalization

$$
\begin{aligned}
& \Delta \chi=\langle\chi(\mathrm{R})\rangle_{\mathrm{GM}}-\chi_{v}(\mathrm{P}) \approx\langle\chi(\mathrm{R})\rangle_{\mathrm{GM}}-\chi_{a}(\mathrm{P}) \\
& \approx 1 / 2\left[D\left(\mathrm{P}^{+}\right)-D\left(\mathrm{P}^{-}\right)\right]
\end{aligned}
$$

As explained in [12], the VS electronegativity does not even require vertical $I$ and $A$ values; thus, we may directly use $\chi_{\mathrm{VS}, a}(\mathrm{P})$ as well. As a rule, the geometric average of the reactant electronegativities, $\langle\chi(\mathrm{R})\rangle_{\mathrm{GM}}$, is larger than the product's electronegativity, $\chi_{v}(\mathrm{P})$, by approximately half the difference of the ionic bond dissociation energies, $1 / 2[D$ $\left(\mathrm{P}^{+}\right)-D\left(\mathrm{P}^{-}\right)$]. Rule 1 follows from Eq. (21), Sanderson's principle is supported (individual deviations: $<10 \%$ ) in association reactions, if $D\left(\mathrm{P}^{+}\right)=D\left(\mathrm{P}^{-}\right)$. This is equivalent to $\mathrm{BO}_{\text {rel }}\left(\mathrm{P}^{+}\right)=\mathrm{BO}_{\text {rel }}\left(\mathrm{P}^{-}\right)$, according to Eqs. (5) and (6).

$\Delta \chi \approx 0, \quad$ if $\left[D\left(\mathrm{P}^{+}\right)-D\left(\mathrm{P}^{-}\right)\right]=\mathrm{BO}_{\text {rel }}\left(\mathrm{P}^{+}\right)-\mathrm{BO}_{\text {rel }}\left(\mathrm{P}^{-}\right)=0$

Let us consider the role of formal bond orders (FBOs) as rough estimates of the bond strength for Rule 2 and Theorem 1. Rule 2 reads: Sanderson's principle is supported (individual deviations: $<10 \%$ ) by association reactions, $\mathrm{X}+\mathrm{Y} \rightarrow \mathrm{XY}$, if the formal bond orders, FBO, of the ions are equal, $\mathrm{FBO}\left(\mathrm{XY}^{+}\right)=\mathrm{FBO}\left(\mathrm{XY}^{-}\right)$. Theorem 1: The electronegativity is not equalized by association reactions, $\mathrm{X}+\mathrm{Y} \rightarrow \mathrm{XY}$, if the formal bond orders of the ions differ, $\Delta \mathrm{FBO}=\mathrm{FBO}\left(\mathrm{XY}^{+}\right)-\mathrm{FBO}\left(\mathrm{XY}^{-}\right) \neq 0$. Can $\mathrm{FBO}$ give additional insight and support for ENE?

Yes, firstly, because $\mathrm{FBO}\left(\mathrm{P}^{+}\right)=\mathrm{FBO}\left(\mathrm{P}^{-}\right)$is a precondition for $D\left(\mathrm{P}^{+}\right)=D\left(\mathrm{P}^{-}\right)$. With the exception of the alkali hydrides, the case $\triangle \mathrm{FBO} \neq 0$ occurs only if (1) an electron is removed from an antibonding MO of the product, e.g., of $\mathrm{O}_{2}$ or the halogen dimers, or (2) an additional electron is placed into a bonding $\mathrm{MO}$ of the $\mathrm{P}^{-}$, e.g., of $\mathrm{B}_{2}{ }^{-}$or $\mathrm{C}_{2}{ }^{-}$. In both cases (1) with $\mathrm{P}^{+}$and (2) with $\mathrm{P}^{-}$, the bond dissociation energy of the GS molecular ion largely surpasses that of the ion carrying the opposite charge, $(1) D\left(\mathrm{P}^{+}\right)>D\left(\mathrm{P}^{-}\right)$ in halogen dimers, or (ii) $D\left(\mathrm{P}^{-}\right)>D\left(\mathrm{P}^{+}\right)$for $\mathrm{B}_{2}$ and $\mathrm{C}_{2}$. The latter cases are discussed in detail in Refs. [11, 12].

Secondly, FBOs give additional support, because they are easier and more often available than the quantitative relative bond orders. For relevant $\mathrm{BO}_{\text {rel }}$ values, the bond dissociation energies, $D\left(\mathrm{P}^{+}\right), D\left(\mathrm{P}^{-}\right)$and $D(\mathrm{P})$, are all required. However, for unstable anions, the $D\left(\mathrm{P}^{-}\right)$is not known to the required accuracy, while the $\mathrm{FBO}\left(\mathrm{P}^{-}\right)$can be assigned, e.g., $\mathrm{FBO}\left(\mathrm{H}_{2}^{-}\right)=1 / 2$.

Table 1 focusses on the accuracy of ENE in diatomic molecules with bond dissociation energies, $D(\mathrm{P}), D\left(\mathrm{P}^{+}\right)$, $D\left(\mathrm{P}^{-}\right)$, and their wide range of $\mathrm{FBO}$ values, $0 \leq \mathrm{FBO} \leq 3$. Many more, in fact 89 diatomic and polyatomic molecules can be discussed for ENE along these lines based on the tables published in [11-13]. Table 1 also includes the differences $\Delta \mathrm{FBO}, \Delta \chi$ and the percentage difference $\delta \chi=100$ $\left\{\left[\langle\chi(\mathrm{R})\rangle_{\mathrm{GM}} / \chi_{v}(\mathrm{P})\right]-\right\}$. The $\chi$ values are obtained from the extended lists of atomic and molecular GS and VS data $\left(I_{v}, A_{v}, \chi, \eta\right)$ in Refs. [11-13]. In Table 1, we document the necessary condition for ENE that the formal bond orders have to be equal: $\mathrm{FBO}\left(\mathrm{P}^{+}\right)=\mathrm{FBO}\left(\mathrm{P}^{-}\right)$. Note that the two Rules and Theorem 1 are valid for $\mathrm{LiH}$, in spite of the cation $\mathrm{LiH}^{+}$being exceptional. $\mathrm{LiH}^{+}$is practically unbound and best described as a $\mathrm{H}$-atom polarized by $\mathrm{Li}^{+}$, thus $\mathrm{FBO}=0$. The $\mathrm{H}_{3} \mathrm{C}-\mathrm{CH}_{3} \sigma$-bond in methane is assessed just by $\mathrm{FBO}$ values, without needing dissociation energies. The methyl radical $\mathrm{R}=\cdot \mathrm{CH}_{3}\left(I_{v}=9.85 \mathrm{eV}, A_{v}=-0.01 \mathrm{eV}\right.$, 
Table 1 Formal bond orders, FBO, the difference $\Delta \mathrm{FBO}=\mathrm{FBO}\left(\mathrm{P}^{+}\right)-\mathrm{FBO}\left(\mathrm{P}^{-}\right)$, ionic bond dissociation energies, $D\left(\mathrm{P}^{+}\right), D\left(\mathrm{P}^{-}\right)$, their difference $1 / 2\left[D\left(\mathrm{P}^{+}\right)-D\left(\mathrm{P}^{-}\right)\right]$, the electronegativity difference, $\Delta \chi=\langle\chi(\mathrm{R})\rangle_{\mathrm{GM}}-\chi_{v}(\mathrm{P})$, and percentage difference $\delta \chi=100\left\{\left[\langle\chi(\mathrm{R})\rangle_{\mathrm{GM}} / \chi_{v}(\mathrm{P})\right]-1\right\}$

\begin{tabular}{|c|c|c|c|c|c|c|c|c|c|}
\hline $\mathrm{P}$ & $\mathrm{FBO}(\mathrm{P})$ & $\mathrm{FBO}\left(\mathrm{P}^{+}\right)$ & $D\left(\mathrm{P}^{+}\right)$ & $\mathrm{FBO}\left(\mathrm{P}^{-}\right)$ & $D\left(\mathrm{P}^{-}\right)$ & $\Delta \mathrm{FBO}$ & $1 / 2\left[D\left(\mathrm{P}^{+}\right)-D\left(\mathrm{P}^{-}\right)\right]$ & $\Delta \chi$ & $\delta \chi(\%)[11,12]$ \\
\hline $\mathrm{H}_{2}$ & 1 & $1 / 2$ & 2.65 & $1 / 2$ & n. a. & 0 & n. a. & 0.19 & 3 \\
\hline $\mathrm{Li}_{2}$ & 1 & $1 / 2$ & 1.44 & $1 / 2$ & $\approx 0.90$ & 0 & 0.27 & 0.20 & 7 \\
\hline $\mathrm{Na}_{2}$ & 1 & $1 / 2$ & 0.96 & $1 / 2$ & $\approx 0.44$ & 0 & 0.26 & 0.07 & 3 \\
\hline $\mathrm{LiNa}$ & 1 & $1 / 2$ & 0.99 & $1 / 2$ & $\approx 0.69$ & 0 & 0.15 & 0.12 & 4 \\
\hline $\mathrm{LiH}$ & 1 & 0 & 0.114 & $1 / 2$ & 2.003 & $-1 / 2$ & -0.944 & 0.60 & 15 \\
\hline \multirow[t]{2}{*}{$\mathrm{N}_{2}$} & \multirow[t]{2}{*}{3} & $\mathrm{GS}: 2 \frac{1}{2}$ & 8.71 & \multirow[t]{2}{*}{$21 / 2$} & \multirow[t]{2}{*}{$\approx 7.53$} & GS:0 & 0.63 & GS:0.61 & 9 \\
\hline & & $\mathrm{VS}: 2^{1} / 2$ & 7.61 & & & VS:0 & $\approx 0.04$ & VS:0.00 & 0 \\
\hline \multirow[t]{2}{*}{ NO } & \multirow[t]{2}{*}{$2^{1 / 2}$} & GS:3 & 10.85 & \multirow[t]{2}{*}{2} & \multirow[t]{2}{*}{5.05} & GS:1 & 2.90 & GS:2.86 & 64 \\
\hline & & VS:2 & 4.44 & & & VS:0 & -0.30 & VS:- 0.12 & -1.4 \\
\hline \multirow[t]{2}{*}{$\mathrm{O}_{2}$} & \multirow[t]{2}{*}{2} & GS:21/2 & 6.66 & \multirow[t]{2}{*}{$1 \frac{1 / 2}{2}$} & \multirow[t]{2}{*}{4.09} & GS:1 & 1.28 & GS:1.19 & 19 \\
\hline & & VS: $1 \frac{1}{2}$ & 4.03 & & & VS:0 & -0.03 & VS:-0.01 & 0 \\
\hline \multirow[t]{2}{*}{$\mathrm{S}_{2}$} & \multirow[t]{2}{*}{2} & GS: $2^{1 / 2}$ & 5.37 & \multirow[t]{2}{*}{$1 \frac{1 / 2}{2}$} & \multirow[t]{2}{*}{3.95} & GS:1 & 0.71 & GS:0.79 & 15 \\
\hline & & VS: $1 \frac{1}{2}$ & 3.52 & & & VS:0 & -0.21 & VS: -0.07 & -1 \\
\hline \multirow[t]{2}{*}{$\mathrm{F}_{2}$} & \multirow[t]{2}{*}{1} & GS: $1 \frac{1 / 2}{2}$ & 3.34 & \multirow[t]{2}{*}{$1 / 2$} & \multirow[t]{2}{*}{1.28} & GS:1 & 1.03 & GS:1.70 & 20 \\
\hline & & $V S: 1 / 2$ & 1.37 & & & VS:0 & 0.05 & VS:0.77 & 7 \\
\hline \multirow[t]{2}{*}{$\mathrm{Cl}_{2}$} & \multirow[t]{2}{*}{1} & GS: $1 \frac{1}{2}$ & 3.95 & \multirow[t]{2}{*}{$1 / 2$} & \multirow[t]{2}{*}{1.26} & GS: 1 & 1.35 & GS:1.91 & 30 \\
\hline & & VS: $1 / 2$ & 1.50 & & & VS:0 & 0.12 & VS:0.30 & 8 \\
\hline \multirow[t]{2}{*}{$\mathrm{IBr}$} & \multirow[t]{2}{*}{1} & GS: $1 \frac{1}{2}$ & 2.42 & \multirow[t]{2}{*}{$1 / 2$} & \multirow[t]{2}{*}{1.1} & GS:1 & 0.65 & GS:1.42 & 25 \\
\hline & & $\mathrm{VS}: 1 / 2$ & 1.08 & & & VS:0 & -0.01 & VS:0.64 & 8 \\
\hline $\mathrm{H}_{3} \mathrm{C}-\mathrm{CH}_{3}$ & 1 & $1 / 2$ & n. a. & $1 / 2$ & n. a. & 0 & n. a. & VS:- 0.10 & -2 \\
\hline
\end{tabular}

The energies and electronegativities are given in electron Volt units (eV). Unless identical, ground-state (GS) and valence-state (VS) data are assigned

$\chi=4.92 \mathrm{eV}[11])$ serves as the group forming the homonuclear bond, $\mathrm{H}_{3} \mathrm{C}-\mathrm{CH}_{3}\left(I_{v}=12.1 \mathrm{eV}, A_{v}=-2.05 \mathrm{eV}\right.$, $\chi=5.02$ [11]). This value is the VS bond electronegativity, not the $\left\langle\chi_{\mathrm{GS}}(\mathrm{at})\right\rangle_{\mathrm{GM}}=6.94 \mathrm{eV}$ of all GS atoms of methane. The latter average is $38 \%$ higher than the here equalized $\chi$ $(\mathrm{R})=4.92 \mathrm{eV}$.

As already documented using the original definitions of $\chi_{\mathrm{VS}}$ and $\chi_{0}$, the overall accuracy of valence-state ENE (VSENE) is about an order of magnitude better than that of the ground-state ENE (GS-ENE) [11, 12]. For the large set of 89 molecules in [11], the mean unsigned deviations (MUD) in $\%$ are $2.55 \%$ for VS-ENE, compared to $21.95 \%$ for GS-ENE. The corresponding increase in accuracy amounts to the factor 8.6 [11]. The present work provides the general explanation for these results. Conceptual DFT has been unable to explain the significant $\chi_{0}$ changes that occur on homonuclear bond formation [1, p. 93]. Theorem 1 classifies precisely: $\chi_{0}\left(\mathrm{X}_{2}\right) \neq \chi_{0}(\mathrm{X})$, if the formal bond orders of the ions differ, FBO $\left(\mathrm{X}_{2}^{+}\right)_{\mathrm{GS}}-\mathrm{FBO}\left(\mathrm{X}_{2}^{-}\right)_{\mathrm{GS}} \neq 0$. Remarkably, the large changes of the external potential, $v(\mathbf{r})$, during bond formation neither affect the Rules and Theorem 1, nor the accuracy of VS-ENE. Thus, the constancy of $v(\mathbf{r})$ is not required. In addition, if the changes of the external potential were the main reason for many exceptions to GS-ENE, it would be hard to explain, why GS-ENE is so well realized, if $\chi_{0}=\chi_{\mathrm{vS}}$, as, e.g., in $\mathrm{H}_{2}$.
We now turn to Theorem 2: The chemical hardness is increased by nonpolar bond formation, $2 \mathrm{X} \rightarrow \mathrm{X}_{2}$, if (for atomic $\mathrm{X}$ : if and only if) the sum $\mathrm{BO}_{\mathrm{rel}}\left(\mathrm{X}_{2}^{+}\right)+\mathrm{BO}_{\mathrm{rel}}\left(\mathrm{X}_{2}^{-}\right)<2$.

While the bond dissociation energy, $D(\mathrm{P})$, of the neutral product does not enter in Eqs. (12)-(22), it assumes an important role in discussing hardness changes, $\Delta \eta(\mathrm{P})=\eta$ $(\mathrm{P})-\langle\eta(\mathrm{R})\rangle_{\mathrm{AM}}$. In proving Theorem 2 , take the difference of Eqs. (10) and (11) to obtain the adiabatic hardness, $\eta_{a}$, of the product

$2 \eta_{a}(\mathrm{P})=I_{a}(\mathrm{P})-A_{a}(\mathrm{P})=2 D(\mathrm{P})-D\left(\mathrm{P}^{+}\right)-D\left(\mathrm{P}^{-}\right)+I(\mathrm{X})-A(\mathrm{Y})$

and focus on the following difference in bond dissociation energies

$\Delta D(\mathrm{P})=2 D(\mathrm{P})-D\left(\mathrm{P}^{+}\right)-D\left(\mathrm{P}^{-}\right)$

The role of $\Delta D$ for the $\mathrm{MH}$ rule in connection with ground-state hardness $\eta_{0}$ has been first recognized by Pal et al. [36, 37]. $\Delta D$ is also very important in connection with $\Delta \eta_{\mathrm{VS}}$ [12]. On the right-hand side of Eq. (23), $I(\mathrm{X})-A(\mathrm{Y})$ is now expressed by $\langle\eta(\mathrm{R})\rangle_{\mathrm{AM}}$ and the electronegativity difference, $\Delta \chi(\mathrm{R}) \geq 0$

$$
\begin{aligned}
I(\mathrm{X})-A(\mathrm{Y}) & =\chi(\mathrm{X})+\eta(\mathrm{X})-[\chi(\mathrm{Y})-\eta(\mathrm{Y})] \\
& =2\langle\eta(\mathrm{R})\rangle_{\mathrm{AM}}-\Delta \chi(\mathrm{R})
\end{aligned}
$$


We obtain the hardness increase $\Delta \eta(\mathrm{P})=\eta(\mathrm{P})-\langle\eta$ $(\mathrm{R})\rangle_{\mathrm{AM}} \geq \eta_{a}(\mathrm{P})-\langle\eta(\mathrm{R})\rangle_{\mathrm{AM}}=\Delta \eta_{a}(\mathrm{P})$ as

$\Delta \eta(\mathrm{P}) \geq \Delta \eta_{a}(\mathrm{P})=1 / 2 \Delta D(\mathrm{P})-1 / 2 \Delta \chi(\mathrm{R}) \leq 1 / 2 \Delta D(\mathrm{P})$

Due to the first law of thermodynamics, Eq. (26) is strictly valid for all association reactions. Theorem 2 deals with $\mathrm{P}=\mathrm{X}_{2}$ in the bond formation, $2 \mathrm{X} \rightarrow \mathrm{X}_{2}$, characterized by $\Delta \chi$ $(\mathrm{R})=0$. In this case, the division of Eq. (26) by $D\left(\mathrm{X}_{2}\right)>0$ gives the relative bond orders on the right-hand side

$\Delta \eta\left(\mathrm{X}_{2}\right) / D\left(\mathrm{X}_{2}\right) \geq 1 / 2\left[2-\mathrm{BO}_{\text {rel }}\left(\mathrm{X}_{2}^{+}\right)-\mathrm{BO}_{\text {rel }}\left(\mathrm{X}_{2}^{-}\right)\right]$

Equation (27) proves Theorem 2 that the chemical hardness is increased by nonpolar bond formation, $2 \mathrm{X} \rightarrow \mathrm{X}_{2}$, if the sum $\mathrm{BO}_{\text {rel }}\left(\mathrm{X}_{2}^{+}\right)+\mathrm{BO}_{\text {rel }}\left(\mathrm{X}_{2}^{-}\right)<2$.

When is $\eta\left(\mathrm{X}_{2}\right)-\eta(\mathrm{X})$ found to be positive? In general, if VS hardness values are used. The situation is significantly different, if ground-state (GS) quantities are used. According to the examples shown in Table 2, the ground states of $\mathrm{X}_{2}{ }^{+}$ and $\mathrm{X}_{2}^{-}$can give $\mathrm{BO}_{\text {rel }}\left(\mathrm{X}_{2}^{+}\right)+\mathrm{BO}_{\text {rel }}\left(\mathrm{X}_{2}^{-}\right)>2$ and thus lead to violations of the $\mathrm{MH}$ rule. This is the case, when (1) an electron is removed from an antibonding MO to form $\mathrm{X}_{2}{ }^{+}$, or (2) the additional electron on $\mathrm{X}_{2}{ }^{-}$is placed into a bonding MO. Nitrogen, $\mathrm{N}_{2}$, is an interesting case with respect to ionization, as both the GS and VS ionizations weaken the bond, reduce $D$ and stretch the bond length, although by different amounts.

Rule 3 The chemical hardness is decreased, $\Delta \eta<0$, thus the "maximum hardness principle" violated by association reactions, $\mathrm{X}+\mathrm{Y} \rightarrow \mathrm{XY}$, if $\mathrm{BO}_{\text {rel }}\left(\mathrm{XY}^{+}\right)+\mathrm{BO}_{\text {rel }}\left(\mathrm{XY}^{-}\right)>2$, that is, if $\Delta D<0$. The essential support follows directly from Eq. (26). If $\Delta D$ turns negative, it is further reduced by $\Delta \chi$ $(\mathrm{R})>0$. Thus, the adiabatic change $\Delta \eta_{a}(\mathrm{XY})$ is definitely negative. Admittedly, with the vertical $\Delta \eta(\mathrm{XY}) \geq \Delta \eta_{a}(\mathrm{XY})$, exceptions could occur, for which $\Delta \eta(\mathrm{XY}) \geq 0$. Nevertheless, no exception to Rule 3 is known to the author. Without any valid exception, Rule 3 could be transformed into a Theorem 3. The reactions shown in Table 2 document the validity of both Theorem 2 and Rule 3.

Table 2 evidences that Pearson's maximum hardness $(\mathrm{MH})$ principle is supported, if VS quantities are considered. The notable exception is $\mathrm{LiH}$, for which the Rule 3 clearly holds, but hardness decreases, and the MH rule fails, in spite of using the VS values. Forming alkali hydride molecules $\mathrm{AH})$ from the atoms significantly reduces the hardness and contradicts $\mathrm{MH}$. The large negative electronegativity differences, $-5.00<\Delta \chi(\mathrm{R})<-4.17 \mathrm{eV}$, overcompensate the positive bond energy differences $\Delta D(\mathrm{AH})>0$, themselves due to the extremely weak $\mathrm{AH}^{+}$bonds, $D\left(\mathrm{AH}^{+}\right) \approx 0.05 \mathrm{eV}$ $[38,39]$. Other exceptional properties of the alkali hydrides

Table 2 Formal bond orders, FBO, bond dissociation energies, $D(\mathrm{P}), D\left(\mathrm{P}^{+}\right), D\left(\mathrm{P}^{-}\right)$, their change, $\Delta D / \mathrm{D}(\mathrm{P})=2-\mathrm{BO}_{\text {rel }}\left(\mathrm{P}^{+}\right)-\mathrm{BO}_{\text {rel }}\left(\mathrm{P}^{-}\right)$, and the hardness increase (from Ref. [13]) $\Delta \eta(\mathrm{P})=\eta(\mathrm{P})-\langle\eta(\mathrm{R})\rangle_{\mathrm{AM}}$

\begin{tabular}{|c|c|c|c|c|c|c|c|c|}
\hline $\mathrm{P}$ & $\mathrm{FBO}(\mathrm{P})$ & $D(\mathrm{P})$ & $\mathrm{FBO}\left(\mathrm{P}^{+}\right)$ & $D\left(\mathrm{P}^{+}\right)$ & $\mathrm{FBO}\left(\mathrm{P}^{-}\right)$ & $D\left(\mathrm{P}^{-}\right)$ & $\Delta D / \mathrm{D}(\mathrm{P})$ & $\Delta \eta_{a} ; \Delta \eta_{v}$ \\
\hline $\mathrm{H}_{2}$ & 1 & 4.48 & $1 / 2$ & 2.65 & $1 / 2$ & n. a. & n. a. & $1.29 a ; 2.76 v$ \\
\hline $\mathrm{Li}_{2}$ & 1 & 1.046 & $1 / 2$ & 1.44 & $1 / 2$ & $\approx 0.88$ & -0.22 & $-0.11 a ;+0.05 v$ \\
\hline $\mathrm{Na}_{2}$ & 1 & 0.737 & $1 / 2$ & 0.96 & $1 / 2$ & $\approx 0.44$ & 0.10 & $0.02 a ; 0.05 v$ \\
\hline $\mathrm{LiNa}$ & 1 & 0.87 & $1 / 2$ & 0.99 & $1 / 2$ & $\approx 0.69$ & 0.07 & $-0.04 a ;+0.02 v$ \\
\hline $\mathrm{LiH}$ & 1 & 2.425 & 0 & 0.114 & $1 / 2$ & 2.003 & +1.13 & $-0.63 a ;-0.64 v$ \\
\hline $\mathrm{N}_{2}$ & 3 & 9.78 & $\begin{array}{l}\text { GS: } 2^{1 / 2} \\
\text { VS: } 2^{1 / 2}\end{array}$ & $\begin{array}{l}8.73 \\
7.61\end{array}$ & $2 \frac{1}{2}$ & $\approx 7.53$ & $\begin{array}{l}\text { GS: }+0.34 \\
\text { VS: }+0.45\end{array}$ & $\begin{array}{l}+1.63 v \\
+3.17 v\end{array}$ \\
\hline NO & $2 \frac{1}{2}$ & 6.50 & $\begin{array}{l}\text { GS: } 3 \\
\text { VS: } 2\end{array}$ & $\begin{array}{l}10.85 \\
4.44\end{array}$ & 2 & 5.05 & $\begin{array}{l}\text { GS: }-0.45 \\
\text { VS: }+0.54\end{array}$ & $\begin{array}{l}-1.98 v \\
+1.76 v\end{array}$ \\
\hline $\mathrm{O}_{2}$ & 2 & 5.116 & $\begin{array}{l}\text { GS: } 2^{1 / 2} \\
\text { VS: } 1 \frac{11 / 2}{}\end{array}$ & $\begin{array}{l}6.663 \\
4.03\end{array}$ & $1 \frac{1}{2}$ & 4.094 & $\begin{array}{l}\text { GS: }-0.103 \\
\text { VS: }+0.41\end{array}$ & $\begin{array}{l}-0.262 v \\
+1.054 v\end{array}$ \\
\hline $\mathrm{S}_{2}$ & 2 & 4.37 & $\begin{array}{l}\text { GS: } 2^{1 / 2} \\
\text { VS: } 1 \frac{112}{2}\end{array}$ & $\begin{array}{l}5.37 \\
3.52\end{array}$ & $1 \frac{1}{2}$ & 3.95 & $\begin{array}{l}\text { GS: }-0.133 \\
\text { VS: }+0.29\end{array}$ & $\begin{array}{l}-0.29 v \\
+0.64 v\end{array}$ \\
\hline $\mathrm{F}_{2}$ & 1 & 1.602 & $\begin{array}{l}\text { GS: } 1 \frac{1}{2} \\
\text { VS: } 1 / 2\end{array}$ & $\begin{array}{l}3.34 \\
1.37\end{array}$ & $1 / 2$ & 1.28 & $\begin{array}{l}\text { GS: }-0.89 \\
\text { VS: } 0.549\end{array}$ & $\begin{array}{l}-0.72 v \\
+0.95 v\end{array}$ \\
\hline $\mathrm{Cl}_{2}$ & 1 & 2.48 & $\begin{array}{l}\text { GS: } 1 \frac{1 / 2}{2} \\
\text { VS: } 1 / 2\end{array}$ & $\begin{array}{l}3.95 \\
1.50\end{array}$ & $1 / 2$ & 1.26 & $\begin{array}{l}\text { GS: }-0.10 \\
\text { VS: }+0.89\end{array}$ & $\begin{array}{l}-0.13 v \\
+1.10 v\end{array}$ \\
\hline $\mathrm{IBr}$ & 1 & 1.82 & $\begin{array}{l}1 / 2 \\
1 / 2\end{array}$ & $\begin{array}{l}2.42 \\
1.08\end{array}$ & $1 / 2$ & 1.12 & $\begin{array}{l}\text { GS: }+0.05 \\
\text { VS: }+0.87\end{array}$ & $\begin{array}{l}+0.31 v \\
+1.18 v\end{array}$ \\
\hline $\mathrm{C}_{2} \mathrm{H}_{6}$ & 1 & 3.87 & $1 / 2$ & n. a. & $1 / 2$ & n. a. & VS: n. a. & $\begin{array}{c}+2.15 v \\
(\text { see text) }\end{array}$ \\
\hline
\end{tabular}

The energy and hardness are given in electron Volt units (eV); subscript $a$ stands for adiabatic and subscript $v$ for vertical. Unless identical, ground-state (GS) and valence-state (VS) data are assigned 
have been already documented by Pauling [40]. The impact of the electronegativity difference between the reactants on the MH rule is discussed quantitatively in [13]. The MH rule is not well fulfilled in terms of GS hardness in association reactions. On the contrary, the $\mathrm{MH}$ rule is violated, as soon as (1) by generating $\mathrm{P}^{+}$the electron is removed from an antibonding $\mathrm{MO}$, or (2) the additional electron on $\mathrm{P}^{-}$is placed into a bonding $\mathrm{MO}$, which is unoccupied in neutral $\mathrm{P}$, e.g., $\mathrm{B}_{2}{ }^{-}$and $\mathrm{B}_{2}$. The rules and theorems presented here allow to understand the reasons of the successes and failures of both the maximum hardness and the electronegativity equalization rules.

\section{Summary}

Theoretical chemistry has been built on three pillars: quantum mechanics, thermodynamics and statistical mechanics [41]. We here emphasize the role of thermodynamics in generating new rules and theorems. New combinations of the fuzzy concepts of bond order, valence states, electronegativity and chemical hardness improve the understanding of the concepts in their contexts and the structural rules and principles connected to them. To broadly validate electronegativity equalization (ENE) and maximum hardness (MH), it is necessary to involve the concepts of bond order and valence states; otherwise, confusions and doubts are generated and too many exceptions to the rules are found. Conceptual DFT should accommodate valence-state energies as planned long ago by Parr and Yang [1]. Changes in external potential, $v$ (r), during the reaction are absorbed in the thermochemical cycles and do not interfere with the ENE and MH rules. Therefore, a restriction to vertical ionization energies and electron affinities in the context of these rules is not mandatory. The present work explains why the overall accuracy of valence-state ENE is about an order of magnitude better than that of the ground-state ENE. The thermochemical cycles further show that the reduction in the bond order by ionization is an important condition for hardness increase in association reactions, $\mathrm{X}+\mathrm{Y} \rightarrow \mathrm{XY}$.

Acknowledgements Open Access funding provided by Projekt DEAL. I thank Dr. Judith Rommel for helping to find the references [34] and [35]. I am grateful to Prof. Dr. Andreas Köhn for his hospitality in the Institut für Theoretische Chemie, Universität Stuttgart. The reviewers are acknowledged for their pertinent comments.

Open Access This article is licensed under a Creative Commons Attribution 4.0 International License, which permits use, sharing, adaptation, distribution and reproduction in any medium or format, as long as you give appropriate credit to the original author(s) and the source, provide a link to the Creative Commons licence, and indicate if changes were made. The images or other third party material in this article are included in the article's Creative Commons licence, unless indicated otherwise in a credit line to the material. If material is not included in the article's Creative Commons licence and your intended use is not permitted by statutory regulation or exceeds the permitted use, you will need to obtain permission directly from the copyright holder. To view a copy of this licence, visit http://creativecommons.org/licenses/by/4.0/.

\section{Appendix}

Electronegativity, the power of an atom in the molecule (AiM) to attract electrons to itself, [40, 42] represents the most frequently applied ordering concept of chemistry. The electron configuration of the AiM differs from that of the free atom in its ground state, e.g., a diatomic molecule, $\mathrm{XY}$, can contain various neutral and/or ionic valence structures. The structures must fulfill the strict Wigner-Witmer correlation rules, which establish symmetry constraints on bond formation and breaking $[15,16]$. The electron pair bond between two atoms, $\mathrm{X}$ and $\mathrm{Y}$, is described by three valence structures, a covalent structure, $\mathrm{X}: \mathrm{Y}$, where the pair is equally shared between the atoms, and the two ionic structures, $\mathrm{X}^{+}: \mathrm{Y}^{-}$and $\mathrm{X}:^{-} \mathrm{Y}^{+}$, with the pair fully shifted to the respective anion, $: \mathrm{Y}^{-}$or $\mathrm{X}^{-}$. Thereby, the valencies $\mathrm{V}$ of the AiM's, $\mathrm{X}$ and $\mathrm{Y}$, are each reduced to $V-1$. This characterizes the Mulliken's VS ionization energy from a half-filled atomic orbital, $I_{\mathrm{VS}}(\mathrm{X}, i)$, and the electron affinity, $A_{\mathrm{VS}}(\mathrm{X}, i)$, the energy gained by adding a second electron to the same half-filled orbital $i$ [6-13]. The bond energy, $D$, is partitioned in contributions by ionic and covalent structures with the weights $c_{j}^{2}(j=1-3)$

$D(\mathrm{X}-\mathrm{Y})=c_{1}^{2} D\left(\mathrm{X}^{+}: \mathrm{Y}^{-}\right)+c_{2}^{2} D\left(\mathrm{X}:{ }^{-} \mathrm{Y}^{+}\right)+c_{3}^{2} D(\mathrm{X}: \mathrm{Y})$

Mulliken postulated the absolute atomic electronegativities as equal, $\chi(\mathrm{X})=\chi(\mathrm{Y})$, if and only if $c_{1}^{2}=c_{2}^{2} \neq 0$. The postulate defines Mulliken's absolute electronegativity ("electroaffinity") [6-13] for the AiM, X, as

$\chi_{\mathrm{M}}(\mathrm{X})=\left[I_{\mathrm{VS}}(\mathrm{X})+A_{\mathrm{VS}}(\mathrm{X})\right]$

The concept of charge-dependent electronegativity, which is equalized by bond formation and charge transfer, has been launched by Sanderson [21, 22]. It has been further developed and expressed in terms of the VB and MO theories [8-13, 23-25, 33, 43-45]. In the concept of charge-dependent orbital electronegativity, the energy, $E_{\mathrm{VS}}\left(\mathrm{X}, n_{i}\right)$, of an AiM is differentiable with respect to the orbital occupation number, $n_{i}$,

$\chi_{\mathrm{VS}}\left(X, n_{i}\right)=-\left[\partial E_{\mathrm{VS}}\left(X, n_{i}\right) / \partial n_{i}\right]$ [6]

At $n_{i}=1$, the value is identical to Mulliken's expression

$\chi_{\mathrm{VS}}\left(\mathrm{X}, n_{i}=1\right)=-\left[\partial E\left(\mathrm{X}, n_{i}\right) / \partial n_{i}\right]_{n=1}=\left[I_{\mathrm{VS}}(\mathrm{X}, i)+A_{\mathrm{VS}}(\mathrm{X}, i)\right]$ 
Generalizing Eq. (30) to molecules, Parr and others [1-3, 24-26] considered the $N_{0}$ electrons of a neutral chemical species, $\mathrm{S}$, in its ground state. The negative value of the electronic chemical potential, $\mu(S)$, itself the partial derivative of the total electronic energy, $E_{\mathrm{GS}}(\mathrm{S}, N, v(\mathbf{r}))$, has been postulated as the "absolute electronegativity" of $S$

$\chi(S)=-\mu(S)=-\left[\partial E_{\mathrm{GS}}(S, N, v(\mathbf{r})) / \partial N\right]_{v(\mathbf{r}), \text { No }}$

The total electronic energy can be treated as a continuous function of the electron number, $N$, if and only if the external potential, $v(\mathbf{r})$, is held constant by clamping the nuclei at fixed positions [1-3, 24-28]. Parr and others approximated the total GS electronic energy, $E_{\mathrm{GS}}$, by a simplified DFT model [1-3, 24-28] dubbed the ground-state parabola (GS parabola) [25]

$E_{\mathrm{GS}}(S, Q)=E_{\mathrm{GS}}\left(S, N_{0}\right)+\chi_{0}(S) Q+1 / 2 \eta_{0}(S) Q^{2}$

where $Q=N_{0}-N$ is the net charge of $S$. The "absolute" ground-state electronegativity, $\chi_{0}(S)$, is here the negative of an operational chemical potential, $\mu_{\mathrm{op}}(S)$,

$\chi_{0}(S)=\frac{1}{2}\left[I_{0, v}(S)+A_{0, v}(S)\right]=-\mu_{\mathrm{op}}(S)$

and $I_{0, v}(S)$ and $A_{0, v}(S)$ are the vertical GS ionization energy and electron affinity, respectively. Conceptual DFT is hereby directly based on measurable ground-state properties of isolated atoms and molecules. For atoms, there is no differentiation between vertical $(v)$ and adiabatic $(a)$ values. For molecules, vertical values are essential in DFT models, as only vertical processes keep the external potential, $\boldsymbol{v}(\mathbf{r})$, frozen as required by DFT [1-3, 24-28]. Extended lists of atomic and molecular ground-state data $\left(I_{0, v}, A_{0, v}, \chi_{0}, \eta_{0}\right)$ are available in Refs. [1, 3, 6-12, 46-48]. Parr et al.'s far reaching generalization [1-3, 24-26] of Sanderson's principle postulates, when atoms of initially different $\chi_{0}(S)$ combine to a molecule, their electronegativities will be equalized to an average value, preferably their geometric average, \langle\rangle$_{\mathrm{GM}}$,

$\chi_{0}\left(S_{\mathrm{mol}}\right)=\left\langle\chi_{0}\left(S_{\mathrm{at}}\right)\right\rangle_{\mathrm{GM}}$

The generalized principle has been called the Sanderson-Parr principle $[11,23]$. However, recent large-scale empirical examinations unveiled alarmingly large deviations from ground-state ENE (GS-ENE) [11, 12, 23]. The main text of the present article sheds new light on the reasons for the large deviations. Conceptual DFT should accommodate the VS energies as planned long ago by Parr and Yang [1].

Parr and Pearson originally defined the chemical hardness of a species $S$ by

$\eta_{0}(S)=1 / 2\left(\partial^{2} E_{\mathrm{GS}}(S, N) / \partial N^{2}\right)_{v(\mathbf{r}), \mathrm{No}}=1 / 2\left[I_{0, v}(S)-A_{0, v}(S)\right]$ as the companion parameter to GS electronegativity $\chi_{0}(S)$ $[1,3,26-28]$. The factor $1 \frac{1}{2}$ has been later frequently omitted, but is kept here for better comparison with the VS hardness.

Recently, the exclusively atomic VS electronegativitypresented in Eq. (31) — has been extended to molecules, XY $[11,12]$. In reference to Mulliken's "electroaffinity scale," the new scale is called "valence-pair-affinity," VPA, symbolized by $\alpha_{\mathrm{VP}}$ [11-13]. The VPA is a charge-dependent pair sharing power based on Ruedenberg's bond theory [14] emphasizing the role of electron pair population. For given VS atoms and their ions as reactants, the relevant product states of $\mathrm{XY}, \mathrm{XY}^{+}$and $\mathrm{XY}^{-}$are determined by the Wigner-Witmer symmetry rules $[15,16]$. The energy difference between, say, $\mathrm{XY}$ and $\mathrm{XY}^{+}$is obtained from (1) theoretical calculations, e.g., [46, 47], (2) molecular photoelectron spectra, e.g., [46-49]. The vertical ionization energy is assigned to the electron removal from a particular bond, $b$, and denoted $I_{\mathrm{b}, v}(\mathrm{XY}, b)$. The bond may be specified in complex molecules as $\sigma-, \pi-, \delta$-bond, according to the local symmetry behavior with respect to the particular bond. The molecular $A_{0, v}(\mathrm{XY})$ values are also defined in agreement with the Wigner-Witmer constraints. The valence-pairaffinity, $\alpha_{\mathrm{VP}}(\mathrm{XY}, b)$, of a bond, $b$, formed by the orbitals $i$ of $\mathrm{X}$ and $j$ of $\mathrm{Y}$, is the VS counterpart of $\chi_{0}(\mathrm{XY})$

$\alpha_{\mathrm{VP}}(\mathrm{XY}, b)=1 / 2\left[I_{b, v}(\mathrm{XY}, b)+A_{0, v}(\mathrm{XY})\right]$

The VPA function is thus a specific charge-dependent generalization of Mulliken's $\chi_{\mathrm{VS}}$ to bonds. The companion parameter of the valence-pair-affinity is the VS hardness

$\eta_{\mathrm{VS}}(\mathrm{XY}, b)=1 / 2\left[I_{b, v}(\mathrm{XY}, b)-A_{0, v}(\mathrm{XY})\right]$

The factor $1 / 2$ is an intrinsic difference between the second partial derivatives of VS and GS energies.

\section{References}

1. Parr RG, Yang W (1989) Density-functional theory of atoms and molecules. Oxford University Press, Oxford

2. Parr RG, Donnelly RA, Levy M, Palke WE (1978) J Chem Phys 68:3801-3807

3. Pearson RG (1997) Chemical hardness. Wiley, Weinheim

4. Mayer I (2007) J Comput Chem 28:204

5. Lyngdoh RHD, Schaefer HF III, Bruce King R (2018) Chem Rev 118:11626

6. Mulliken RS (1934) J Chem Phys 2:782

7. Pritchard HO, Skinner HA (1955) Chem Rev 55:745

8. Bratsch G (1988) J Chem Educ 65:34

9. von Szentpály L (1991) J Mol Struct (Theochem) 233:71-81

10. Bergmann D, Hinze J (1996) Angew Chem Int Ed Engl 35:150 with earlier references quoted therein

11. von Szentpály L (2018) J Comput Chem 39:1949

12. von Szentpály L (2015) J Phys Chem A 119:1715

13. von Szentpály L (2017) J Mol Model 23:217

14. Ruedenberg K (1962) Rev Mod Phys 34:326 
15. Wigner E, Witmer EE (1928) Z Phys 51:859-886

16. Herzberg G (1950) Molecular spectra and molecular structure. Vol. 1. Spectra of diatomic molecules. Van Nostrand, Princeton, pp 315-322

17. Huber KP, Herzberg G (1979) Molecular spectra and molecular structure. Vol. 4. Constants of diatomic molecules. Van Nostrand, New York

18. Chen ES, Chen ECM (2002) J Phys Chem A 106:28

19. Chen ES, Chen ECM (2003) J Phys Chem A 107:169

20. Chen ECM, Chen ES (2004) J Chromatogr A 1037:83

21. Sanderson RT (1951) Science 114:670-672

22. Sanderson RT (1983) Polar covalence. Academic Press, New York

23. Datta D, Shee NK, von Szentpály L (2013) J Phys Chem A 117:200

24. Geerlings P, De Proft F, Langenacker W (2003) Chem Rev 103:1793 with earlier references quoted therein

25. Parr RG, von Szentpály L, Liu S (1999) J Am Chem Soc 121:1922

26. Parr RG, Pearson RG (1983) J Am Chem Soc 105:7512

27. Pearson RG (1990) Coord Chem Rev 100:403

28. Pearson RG (1993) Acc Chem Res 26:250

29. Hati S, Datta D (1992) J Org Chem 57:6056-6057

30. Chattaraj PK, Liu GH, Parr RG (1995) Chem Phys Lett 237:171

31. Poater J, Swart M, Solà M (2012) J Mex Chem Soc 56:311

32. Pan S, Solà M, Chattaraj PK (2013) J Phys Chem A 117:1843

33. Bratsch GJ (1988) J Chem Educ 65:223-227

34. Rodin B (2017) Rocky Mt J Math 47:637

35. Aldaz JM (2013) Stat Prob Lett 83:1416

36. Pal S, Roy R, Chandra AK (1994) J Phys Chem 98:2314

37. Pal S, Chandra AK, Roy R (1996) J Mol Struct (Theochem) $361: 57$
38. Fuentealba P, Preuss H, Stoll H, von Szentpály L (1982) Chem Phys Lett 89:418

39. von Szentpály L, Fuentealba P, Preuss H, Stoll H (1982) Chem Phys Lett 93:555

40. Pauling L (1960) The nature of the chemical bond. Cornell University Press, Ithaca

41. Primas H, Müller-Herold U (1984) Elementare Quantenchemie. Teubner, Stuttgart, $\mathrm{p} 14 \mathrm{ff}$

42. Pauling L (1932) J Am Chem Soc 54:3570

43. Pritchard HO, Sumner FH (1956) Proc R Soc A (Lond) 235:136

44. Iczkowski RP, Margrave JL (1961) J Am Chem Soc 83:3547

45. Hinze J, Jaffé HH (1962) J Am Chem Soc 84:540

46. Turner DW, Baker C, Baker AD, Brundle CR (1970) Molecular photoelectron spectroscopy. Wiley, London

47. Johnson RD III (ed) (2015) NIST computational chemistry comparison and benchmark database, NIST standard reference database number 101, release 17b. National Institute of Standards and Technology, Gaithersburg

48. Haynes WM, Lide DR (eds) (2011) Handbook of chemistry and physics, 92nd edn. CRC Press, Boca Raton

49. Lias SG, Bartmess JE, Liebman JF, Holmes JL, Levin RD, Mallard WG (2015) Ion energetics data in NIST chemistry webbook; NIST standard reference database number 69. National Institute of Standards and Technology, Gaithersburg, MD. http://webbo ok.nist.gov/chemistry. Accessed Oct 2019

Publisher's Note Springer Nature remains neutral with regard to jurisdictional claims in published maps and institutional affiliations. 